\title{
LD-Pumped Random Fiber Laser Based on Erbium-Ytterbium Co-Doped Fiber
}

\author{
Qingyang $\mathrm{MENG}^{1}$, Han $\mathrm{WU}^{1}$, Bing $\mathrm{HAN}^{1}$, Jiaqi $\mathrm{LI}^{1}$, and Zinan $\mathrm{WANG}^{1,2^{*}}$ \\ ${ }^{1}$ Key Lab of Optical Fiber Sensing \& Communications, University of Electronic Science \&Technology of China, \\ Chengdu 611731, China \\ ${ }^{2}$ Center for Information Geoscience, University of Electronic Science and Technology of China, Chengdu 611731, China \\ *Corresponding author: Zinan WANG_E-mail: znwang@uestc.edu.cn
}

\begin{abstract}
In this paper, a cladding-pumped erbium-ytterbium co-doped random fiber laser (EYRFL) operating at $1550 \mathrm{~nm}$ with high power laser diode (LD) is proposed and experimentally demonstrated for the first time. The laser cavity includes a 5-m-long erbium-ytterbium co-doped fiber that serves as the gain medium, as well as a 2-km-long single-mode fiber (SMF) to provide random distributed feedback. As a result, stable $2.14 \mathrm{~W}$ of $1550 \mathrm{~nm}$ random lasing at $9.80 \mathrm{~W}$ of $976 \mathrm{~nm}$ LD pump power and a linear output with the slope efficiency as $22.7 \%$ are generated. This simple and novel random fiber laser could provide a promising way to develop high power $1.5 \mu \mathrm{m}$ light sources.
\end{abstract}

Keywords: Random fiber laser; erbium-ytterbium co-doped; cladding pumping

Citation: Qingyang MENG, Han WU, Bing HAN, Jiaqi LI, and Zinan WANG, "LD-Pumped Random Fiber Laser Based on Erbium-Ytterbium Co-Doped Fiber," Photonic Sensors, 2020, 10(2): 181-185.

\section{Introduction}

Random fiber lasers (RFLs) operating via the Rayleigh scattering along a single mode fiber (SMF) as the random distributed feedback attract a great deal of attention since the first demonstration in $2010[1,2]$. This kind of random lasers has certain advantages, such as single transverse mode output, long-distance signal delivery ability, low intensity noise, cavity simplicity, and high lasing efficiency. With the good laser performance and relative simplicity of implementation, RFLs have also been proved to be an important novel light source for optical communications [3, 4], imaging [5-8], and high power applications [9-13]. In recent works, RFLs have been tailored to be multi-wavelength [14, $15]$, wavelength tunable [16, 17], narrow bandwidth $[18,19]$, polarized output [20-23], high efficiency, and high output power [24-27].

Hundred-watt-level high power RFLs operating at $1 \mu \mathrm{m}$ regime have been reported, with high power laser as the pump sources [11, 12]. As for the "eye-safe" and "telecommunication" wavelength range around $1.5 \mu \mathrm{m}$, it has been widely applied in optical communications, light detection and ranging (LIDAR), medical research, etc. However, the reported maximum output power of $1.5 \mu \mathrm{m}$ RFL is below $2 \mathrm{~W}[15,28]$. An alternative way to realize the $1.5 \mu \mathrm{m}$ RFL is utilizing the active fiber, such as erbium-doped fiber (EDF) [29, 30]. This kind of RFL utilizes EDF to provide gain, and a long single mode fiber (SMF) is connected after the EDF to provide sufficient Rayleigh feedback. For erbium-doped RFLs, the threshold could be reduced to tens of milliwatts. However, the loss introduced in the long SMF will decrease the laser efficiency,

Received: 16 January 2018 / Revised: 21 March 2019

(C) The Author(s) 2019. This article is published with open access at Springerlink.com

DOI: $10.1007 / \mathrm{s} 13320-019-0553-\mathrm{x}$

Article type: Regular 
resulting in the low slope efficiency (less than 15\%), and the output power of erbium-doped RFL is quite low $(<500 \mathrm{~mW})$ [29, 31]. For Raman gain or erbium-Raman hybrid gain based RFLs, the laser efficiency could be high ( $>60 \%)$ with the proper cavity design $[15,28]$. However, the pump used in these systems is $1.4 \mu \mathrm{m}$, and the restricted $1.4 \mu \mathrm{m}$ pump power is the main limitation for further power scaling. In recent years, cladding-pumped erbium-ytterbium co-doped fibers are emerging as the preferred choice for high-power fiber lasers around $1.5 \mu \mathrm{m}$ which can be pumped by the high power LD source [32-34]. However, there is no research about RFLs based on erbium-ytterbium co-doped fiber until now.

Here, in this paper, we propose and experimentally demonstrate a cladding-pumped erbium-ytterbium co-doped random fiber laser (EYRFL) with the $976 \mathrm{~nm}$ LD pump. The output power of $1550 \mathrm{~nm}$ random lasing is $2.14 \mathrm{~W}$ at $9.80 \mathrm{~W}$ LD pump power. This paper provides a promising way to increase the output power of $1.5 \mu \mathrm{m}$ RFLs.

\section{Experimental setup and principle}

Figure 1 shows the schematic setup of the proposed system. The multimode $976 \mathrm{~nm}$ LD is used as the pump source. The LD pump is injected into $5 \mathrm{~m}$ double-cladding erbium-ytterbium co-doped fiber $(6 / 125 \mu \mathrm{m})$ through a $(2+1) \times 1$ pump combiner. A section of standard single-mode fiber (SMF) with $2 \mathrm{~km}$ length which provides random Rayleigh distributed feedback is attached after erbiumytterbium co-doped fiber. An FBG with the $1550 \mathrm{~nm}$ center wavelength is connected at the signal port of the combiner, forming the half open cavity for the (EYRFL). The laser output is measured at the

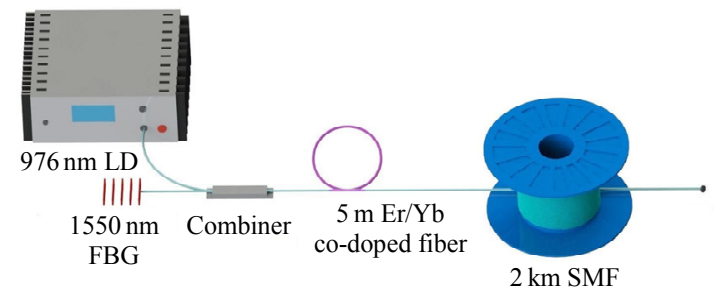

Fig. 1 Configuration of proposed EYRFL. far end of the SMF. To record the spectrum, we connect a 1:99 optical coupler to the end of the SMF and use the $1 \%$ port as a monitor port.

In the EYRFL system, the pumped erbiumytterbium co-doped fiber can provide the gain for random lasing. Figure 2 shows the energy level diagram of erbium-ytterbium co-doped system. With the $976 \mathrm{~nm}$ LD pump, the $\mathrm{Yb}^{3+}$ ions in the ${ }^{2} \mathrm{~F}_{7 / 2}$ level absorb the pump photons, and jump to the ${ }^{2} \mathrm{~F}_{5 / 2}$ level, and transfer energy to the neighboring $\mathrm{Er}^{3+}$ ions in the ${ }^{4} \mathrm{I}_{15 / 2}$ level further. The $\mathrm{Er}^{3+}$ ions in the ${ }^{4} \mathrm{I}_{15 / 2}$ level absorb the pump photons and the excited $\mathrm{Yb}^{3+}$ ions, and then excite them to the ${ }^{4} \mathrm{I}_{11 / 2}$ level. The excited $\mathrm{Er}^{3+}$ ions will quickly relax to the metastable level ${ }^{4} \mathrm{I}_{11 / 2}$ due to the short lifetime of the ${ }^{4} \mathrm{I}_{11 / 2}$ level. The signal is amplified through the stimulated transitions between the ${ }^{4} \mathrm{I}_{13 / 2}$ level and ${ }^{4} \mathrm{I}_{15 / 2}$ level. $\mathrm{C}_{\text {up }}$ is the up-conversion process taking place between Er-ions which has been discussed in previous work [35-37].

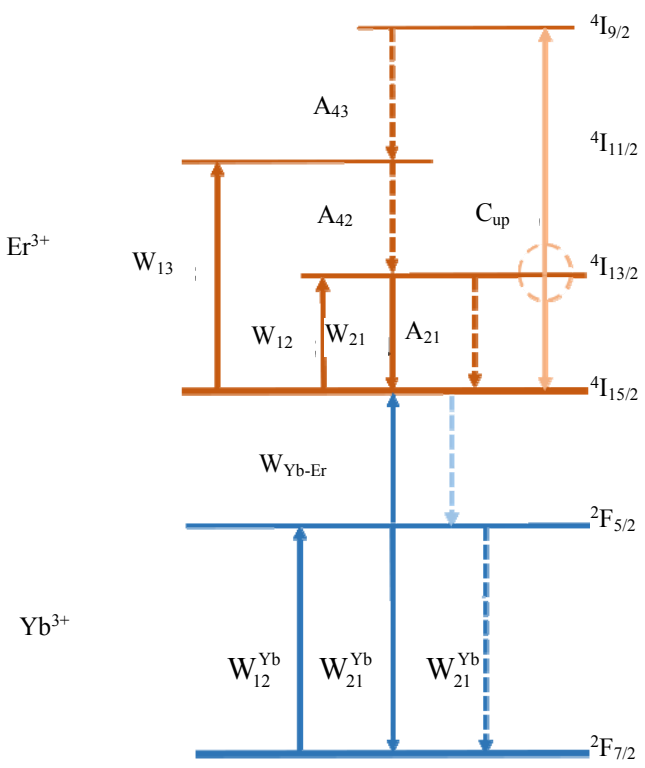

Fig. 2 Energy-level diagram of erbium-ytterbium co-doped system.

Compared with the ordinary EDF, the introduction of appropriate $\mathrm{Yb}^{3+}$ ions can not only effectively suppress the concentration quenching of $\mathrm{Er}^{3+}$ ions (i.e., increase the permissible $\mathrm{Er}^{3+}$ concentration) and increase the pump absorption, 
but also transfer pump energy from $\mathrm{Yb}$-ions to Er-ions non-radioactively, which then emit around $1.55 \mu \mathrm{m}$ [35].

With the $976 \mathrm{~nm}$ pump, the amplified spontaneous emission (ASE) light around $1550 \mathrm{~nm}$ can be stimulated in erbium-ytterbium co-doped fiber. The $1550 \mathrm{~nm}$ light will propagate to the SMF and experience the random distributed Rayleigh feedback in SMF. Therefore, in this way, by combining the FBG and the random distributed Rayleigh feedback, the $1550 \mathrm{~nm}$ random lasing can be stimulated with the help of the erbium-ytterbium co-doped gain. All the fiber ends are angle-cleaved to avoid the unwanted backward reflection.

\section{Results and discussion}

Figure 3 shows the output spectrums at different pump power levels. The spectrum is measured by an optical spectrum analyzer (OSA, Ando AQ6317B) with $0.01 \mathrm{~nm}$ resolution. The lasing spectrum is unstable with a large amount of narrow spikes appearing randomly at $1.05 \mathrm{~W}$ pump power. After increasing the pump power, the spectrum becomes stabilized and smooth, but the base of the spectrum (20 dB bandwidth) rises significantly. When the pump power reaches $9.80 \mathrm{~W}$, the $3 \mathrm{~dB}$ bandwidth of the spectrum is about $0.16 \mathrm{~nm}$.

Figure 4 shows the experimentally measured output power of the $1550 \mathrm{~nm}$ random lasing versus launched pump power. The launched LD pump power is measured after the pump combiner. The threshold of the EYRFL is $0.6 \mathrm{~W}$. After the pump power is increased over the threshold, the lasing power increases linearly as expected with the slope efficiency of about $22.7 \%$. The maximum output power of $1550 \mathrm{~nm}$ random lasing is $2.14 \mathrm{~W}$ at $9.80 \mathrm{~W}$ LD pump power. It could be inferred that the output power could be further increased with the more powerful pump. Also, the laser efficiency could be improved by optimizing the erbiumytterbium co-doped fiber and SMF's length.

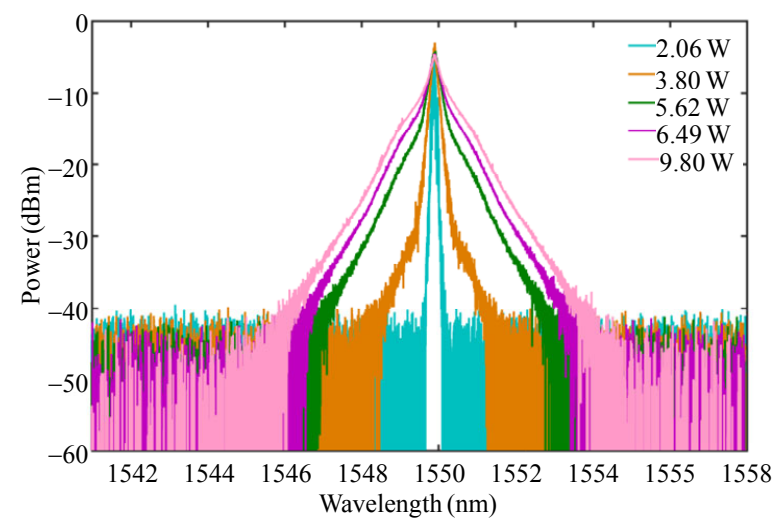

Fig. 3 Measured lasing spectral evolution with different pump powers.

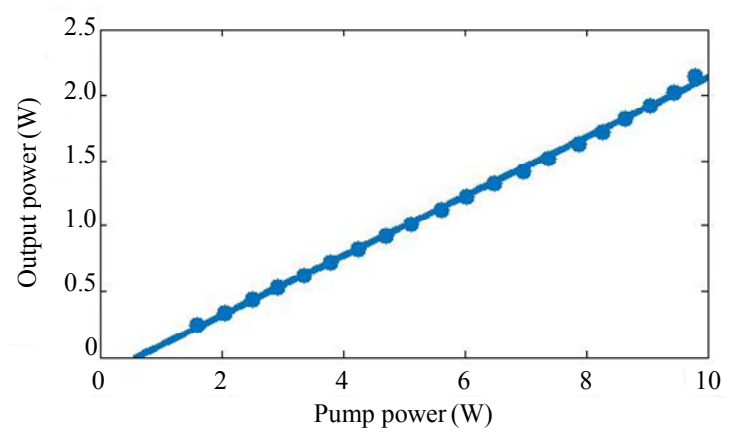

Fig. 4 Output lasing power versus LD pump power.

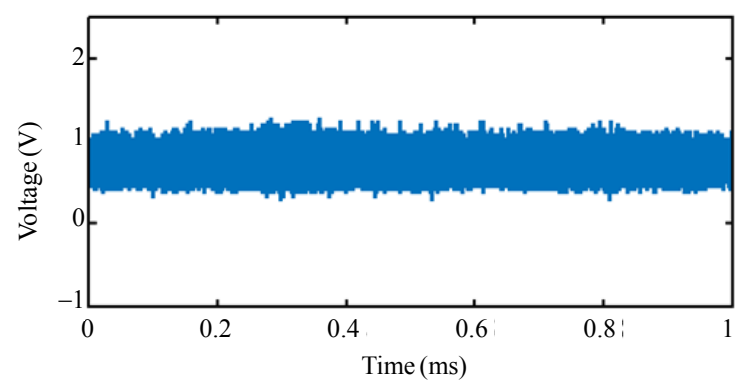

Fig. 5 Time-domain behavior of the EYRFL.

The time domain characteristic of the output lasing is measured by an InGaAs photodetector with $10 \mathrm{MHz}$ bandwidth and an oscilloscope with $500 \mathrm{MHz}$ sampling rate. Figure 5 shows the time domain properties of the $1550 \mathrm{~nm}$ lasing at $9.80 \mathrm{~W}$ of LD pump power. The lasing exhibits quasi-CW output behavior, without significant amplitude fluctuation. Therefore, the stable $1550 \mathrm{~nm}$ random lasing is achieved in this simple cavity design.

The output power of Raman gain or erbium-Raman hybrid gain based RFLs is limited by low $1.4 \mu \mathrm{m}$ pump power. As for erbium-doped RFLs, the output power is restricted by conversion 
efficiency. In this paper, we propose and experimentally demonstrate an EYRFL cladding pumped by the $976 \mathrm{~nm}$ LD pump. The output power is $2.14 \mathrm{~W}$ which is believed to be the highest value ever reported for $1550 \mathrm{~nm}$ RFLs. A linear output with the slope efficiency as $22.7 \%$ is achieved, which has the potential to realize ten-watt-level $1550 \mathrm{~nm}$ RFLs with more powerful LD pumps and higher splicing quality.

\section{Conclusions}

In conclusion, we have proposed and experimentally demonstrated a cladding-pumped EYRFL that can generate $1550 \mathrm{~nm}$ random lasing utilizing high power LD source for the first time. With the $976 \mathrm{~nm}$ LD pump, the $1550 \mathrm{~nm}$ random lasing is achieved via the gain provided by erbium-ytterbium co-doped fiber and the random Rayleigh feedback in passive SMF. With the pump power increasing, the laser spectrum becomes stable and smooth and the base of the spectrum broadens significantly. As a result, with 5-m erbium-ytterbium co-doped fiber and 2-km SMF, $2.14 \mathrm{~W}$ of $1550 \mathrm{~nm}$ random lasing at $9.80 \mathrm{~W}$ of $976 \mathrm{~nm} \mathrm{LD}$ pump power is generated successively, and the slope efficiency of the linear output is $22.7 \%$. The power scaling of the laser can be further realized with more powerful LD pumps. The proposed EYRFL provides the promising way to further increase the power of $1.5 \mu \mathrm{m}$ random lasing, which has the potential value in the field of optical communications and LIDAR.

\section{Acknowledgment}

This work is supported by the National Natural Science Foundation of China (Grant Nos. 61635005, 61205048, and 61290312), the PCSIRT project (Grant No. IRT1218), the 111 project (Grant No. B14039), and the Sichuan Youth Science and Technology Foundation (Grant No. 2016JQ0034).

Open Access This article is distributed under the terms of the Creative Commons Attribution 4.0 International License (http://creativecommons.org/licenses/by/4.0/), which permits unrestricted use, distribution, and reproduction in any medium, provided you give appropriate credit to the original author(s) and the source, provide a link to the Creative Commons license, and indicate if changes were made.

\section{References}

[1] S. K. Turitsyn, S. A. Babin, A. E. El-Taher, P. Harper, D. V. Churkin, S. I. Kablukov, et al., "Random distributed feedback fiber laser," Nature Photonics, 2010, 4: 231-235.

[2] D. V. Churkin, S. Sugavanam, I. D. Vatnik, Z. Wang, E. V. Podivilov, S. A. Babin, et al., "Recent advances in fundamentals and applications of random fiber lasers," Advances in Optics and Photonics, 2015, 7(3): 516-569.

[3] J. Nuño, M. Alcon-Camas, and J. D. Ania-Castañón, "RIN transfer in random distributed feedback fiber lasers," Optics Express, 20(24): 27376-27381.

[4] M. Tan, P. Rosa, S. T. Le, Md. A. Iqbal, I. D. Phillips, and P. Harper, "Transmission performance improvement using random DFB laser based Raman amplification and bidirectional second-order pumping," Optics Express, 2016, 24(3): 2215-2221.

[5] B. Redding, M. A. Choma, and H. Cao, "Speckle-free laser imaging using random laser illumination," Nature Photonics, 2012, 6(6): 355-359.

[6] B. Redding, P. Ahmadi, V. Mokan, M. Seifert, M. A. Choma, and H. Cao, "Low-spatial-coherence high-radiance broadband fiber source for speckle free imaging," Optics Letters, 2015, 40(20): 4607-4610,

[7] A. S. L. Gomes, B. C. Lima, P. I. R. Pincheira, A. L. Moura, M. Gagné, E. P. Raposo, et al., "Glassy behavior in a one-dimensional continuous-wave erbium-doped random fiber laser," Physical Review A, 2016, 94(1): 011801.

[8] R. Ma, Y. J. Rao, W. L. Zhang, and B. Hu, "Multimode random fiber laser for speckle-free imaging," IEEE Journal of Selected Topics in Quantum Electronics, 2019, 25(1): 0900106.

[9] H. Zhang, P. Zhou, X. Wang, X. Du, H. Xiao, and X. $\mathrm{Xu}$, "Hundred-watt-level high power random distributed feedback Raman fiber laser at $1150 \mathrm{~nm}$ and its application in mid-infrared laser generation," Optics Express, 2015, 23(13): 17138-17144.

[10] X. Du, H. Zhang, P. Ma, H. Xiao, X. Wang, P. Zhou, and Z. Liu, "Kilowatt-level fiber amplifier with spectral-broadening-free property, seeded by a random fiber laser," Optics Letters, 2015, 40(22): 5311-5314.

[11] J. M. Xu, J. Ye, P. Zhou, J. Y. Leng, H. Xiao, H. W. ZHANG, et al., "Tandem pumping architecture enabled high power random fiber laser with near-diffraction-limited beam quality," Science China Technological Sciences, 2019, 62(1): 80-86.

[12] H. Zhang, J. Ye, P. Zhou, X. L. Wang, J. Y. Leng, J. 
M. Xu, et al., "Tapered-fiber-enabled high-power, high-spectral-purity random fiber lasing," Optics Letters, 2018, 43(17): 4152-4155.

[13] Z. Wang, H. Wu, M. Fan, L. Zhang, Y. Rao, W. Zhang, et al., "High power random fiber laser with short cavity length: theoretical and experimental investigations," IEEE Journal of Selected Topics in Quantum Electronics, 2015, 21(1): 10-15.

[14] S. Sugavanam, Z. Yan, V. Kamynin, A. Kurkov, L. Zhang, and D. V. Churkin, "Multiwavelength generation in a random distributed feedback fiber laser using an all fiber Lyot filter," Optics Express, 2014, 22(3): 2839-2844.

[15]A. E. El-Taher, P. Harper, S. A. Babin, D. V. Churkin, E. V. Podivilov, J. D. Ania-Castanon, et al., "Effect of Rayleigh-scattering distributed feedback on multiwavelength Raman fiber laser generation," Optics Letters, 2011, 36(2): 130-132.

[16] L. Zhang, H. Jiang, X. Yang, W. Pan, and Y. Feng, "Ultra-wide wavelength tuning of a cascaded Raman random fiber laser," Optics Letters, 2016, 41(2): 215-218.

[17] J. Ye, J. Xu, J. Song, H. S. Wu, H. W. Zhang, J. Wu, et al., "Spectrum-agile hundred-watt-level high-power random fiber laser enabled by watt-level tunable optical filter," Applied Physics Express, 2018, 11(6): 062704.

[18] D. Leandro, S. Rota-Rodrigo, D. Ardanaz, and M. Lopez-Amo, "Narrow-linewidth multi-wavelength random distributed feedback laser," Journal of Lightwave Technology, 2015, 33(17): 3591-3596.

[19] T. Zhu, X. Bao, and L. Chen, "A self-gain random distributed feedback fiber laser based on stimulated Rayleigh scattering," Optics Communications, 2012, 285(6): 1371-1374.

[20] E. A. Zlobina, S. I. Kablukov, and S. A. Babin, "Linearly polarized random fiber laser with ultimate efficiency," Optics Letters, 2015, 40(17): 4074-4077.

[21] S. A. Babin, E. A. Zlobina, S. I. Kablukov, and E. V. Podivilov "High-order random Raman lasing in a PM fiber with ultimate efficiency and narrow bandwidth," Scientific Reports, 2016, 6: 22625.

[22] J. Ye, J. Xu, J. Song, H. Y. Xu, H. S. Wu, H. W. Zhang, et al., "Power scalability of linearly polarized random fiber laser through polarization-rotationbased Raman gain manipulation," Optics Express, 2018, 26(18): 22894-22903.

[23] J. Xu, Z. Lou, J. Ye, J. Wu, J. Leng, H. Xiao, et al., "Incoherently pumped high-power linearly-polarized single-mode random fiber laser: experimental investigations and theoretical prospects," Optics Express, 2017, 25(5): 5609-5617.

[24]I. D. Vatnik, D. V. Churkin, E. V. Podivilov, and S. A. Babin, "High efficiency generation in a short random fiber laser," Laser Physics Letters, 2014, 11(7): 075101 .
[25] X. Du, H. Zhang, X. Wang, P. Zhou, and Z. Liu, "Short cavity-length random fiber laser with record power and ultrahigh efficiency," Optics Letters, 2016, 41(3): 571-574.

[26]H. Wu, Z. Wang, M. Fan, L. Zhang, W. Zhang, and Y. Rao, "Role of the mirror's reflectivity in forward-pumped random fiber laser," Optics Express, 2015, 23(2): 1421-1427.

[27] H. Zhang, P. Zhou, H. Xiao, and X. Xu, "Efficient Raman fiber laser based on random Rayleigh distributed feedback with record high power," Laser Physics Letters, 2014, 11(11): 075104.

[28] H. Wu, Z. N. Wang, W. Sun, et al., "1.5 $\mu \mathrm{m}$ Low threshold, high efficiency random fiber laser with hybrid erbium-Raman gain," Journal of Lightwave Technology, 2018, 36(4): 844-849.

[29] L. Wang, X. Dong, P. Shum, and H. Su, "Tunable erbium-doped fiber laser based on random distributed feedback," IEEE Photonics Journal, 2014, 6(5): 1-5.

[30] L. L. Wang, X. Y. Dong, P. P. Shum, C. Q. Huang, H. and B. Su, "Erbium-doped fiber laser with distributed Rayleigh output mirror," Laser Physics, 2014, 24(11): 115101.

[31] S. Sugavanam, M. Z. Zulkifli and D. V. Churkin, "Multi-wavelength erbium/Raman gain based random distributed feedback fiber laser," Laser Physics, 2016, 26(1): 015101.

[32] J. E. Townsend, W. L. Barnes, K. P. Jedrzejewski, and S. G. Grubb, "Yb sensitised Er doped silica optical fiber with ultrahigh transfer efficiency and gain," Electronics Letters, 1991, 27(21): 1958-1959.

[33] J. Nilsson, S. U. Alam, J. A. Alvarez-Chavez, P. W. Turner, A. A. Clarkson, and A. B. Grudinin, "” IEEE Journal of Quantum Electronics, 2003, 39(8): 987-994.

[34] J. W. Kim, P. Jelger, J. K. Sahu, F. Laurell, and W. A. Clarkson, "High-power and wavelength-tunable operation of an $\mathrm{Er} / \mathrm{Yb}$ fiber laser using a volume Bragg grating," Optics Letters, 2008, 33(11): 1204-1206.

[35] Q. Han, J. Ning, and Z. Sheng, "Numerical investigation of the ASE and power scaling of cladding-pumped Er-Yb codoped fiber amplifiers," IEEE Journal of Quantum Electronics, 2010, 46(11): 1535-1541.

[36] F. D. Pasquale, "Modeling of highly-efficient grating-feedback and Fabry-Perot $\mathrm{Er}^{3+}-\mathrm{Yb}^{3+}$ co-doped fiber lasers," IEEE Journal of Quantum Electronics-Institute Electrical and Electronic Engineers, 1996, 32(2): 326-332.

[37] M. Karasek, "Optimum design of $\mathrm{Er}^{3+}-\mathrm{Yb}^{3+}$, codoped fibers for large-signal high-pump-power applications," IEEE Journal of Quantum Electronics, 33(10): 1699-1705. 